\title{
Oral Cobalamin Therapy for the Patient with Biermer's Disease
}

\author{
Emmanuel Andrès
}

Department of Internal Medicine, University Hospital of Strasbourg, Strasbourg, France

*Corresponding author: Emmanuel Andrès, Department of Internal Medicine, University Hospital of Strasbourg, Strasbourg, France, Tel: 33-03-88-11-50-66; Fax: 33-03-88-11-62-62; E-mail: emmanuel.andres@chru-strasbourg.fr

Rec date: January 5, 2017; Acc date: January 27, 2017; Pub date: February 3, 2017

Copyright: (C) 2017 Andres E. This is an open-access article distributed under the terms of the Creative Commons Attribution License, which permits unrestricted use, distribution, and reproduction in any medium, provided the original author and source are credited.

Citation: Andres E (2017) Oral Cobalamin Therapy for the Patient with Biermer's Disease. J Blood Disord Transfus 8: e117. doi:10.4172/2155-9864.1000e117

\section{Editorial}

Biermer's disease also called: Addison's anemia or in old textbooks, pernicious anemia, is an autoimmune disease, caused by impaired absorption of cobalamin (vitamin B12) owing to the neutralization of intrinsic factor action in the setting of immune atrophic gastritis [1]. In adults and elderly patients, this form of megaloblastic anemia is one of the leading causes of cobalamin deficiency, with the recent described and recognized disorder called food-cobalamin malabsorption. Biermer's disease, as several autoimmune disorders, has a genetic component.

In clinical practice, Biermer's anemia is responsible of several hematologic and neurologic manifestations, typically macrocytic anemia and medullar sclerosis, related to the cobalamin deficiency. Biermer's disease is associated with several autoimmune diseases such as Sjögren' s syndrome, Hashimoto's disease, type 1 diabetes mellitus, and celiac disease [2]. His diagnosis is based on: the presence of intrinsic factor antibodies in serum (specificity: >98\%; sensitivity: $50 \%)$ or the presence of autoimmune atrophic gastritis in gastric biopsies (especially in fundi area). The presence of Helicobacter pylori infection in gastric biopsies may be considered as an exclusion factor.

To date, treatment of cobalamin deficiency related to Biermer's disease is based on parenteral vitamin B12, administered intramuscularly, under the form of cyanocobalamin, hydroxocobalamin, or methylcobalamin [3]. In France, only intramuscular cyanocobalamin is used for this indication (authorization of the French regulatory agency of drug use). A theoretically superiority of hydroxocobalamin has been advanced in relation to better tissue uptake and storage than the other forms [4].

Attitudes regarding the dosage and frequency of administration are very different from one country and to another. In France, vitamin B12 (e.g. cyanocobalamin) therapy follows the scheme: acute treatment at a dose of: $1,000 \mu \mathrm{g}$ daily for 1 week; followed by $1,000 \mu \mathrm{g}$ per week for 1 month; then a monthly dose of $1,000 \mu \mathrm{g}$ for all life. In the United States and the United Kingdom, the doses range from 100-1,000 $\mu \mathrm{g} / \mathrm{month}$, in all cases for life.

Recently, several groups in Sweden, Switzerland, Canada, USA and France have documented the efficacy of oral cobalamin therapy, particularly in case of food-cobalamin malabsorption with a cyanocobalamin doses range from $250-500 \mu \mathrm{g} /$ day [5].

In Biermer's disease, the doses theoritically administered should in all cases greatly exceed those required physiologically (mean require of $2.5 \mu \mathrm{g}$ per day) and for food-cobalamin malabsorption, ranging from $1,000-2,000 \mu \mathrm{g} /$ day of cyanocobalamin [5,6]. Importantly, it is to note that $1 \%$ or oral cobalamin therapy is absorbed by a passive mechanism of diffusion (independent of intrinsic factor and amion less-cubilin complex). In an open-label, prospective study, including patients with established Biermer's disease $(n=10)$, we have documented the efficacy and tolerability of oral crystalline cyanocobalamin $1,000 \mu \mathrm{g} /$ day [7]. After 3 months of treatment, serum cobalamin concentration increased significantly in $90 \%$ of the patients (mean [SD] increase, 117.4 [30.8] pg/mL; $\mathrm{p}<0.001$ vs. baseline). Serum cobalamin concentrations were normalized $(>200 \mathrm{pg} / \mathrm{mL}$ ) in $60 \%$. Eighty percent of the patients had increased hemoglobin concentrations (mean [SD] increase, $2.5[2.4] \mathrm{g} / \mathrm{dL} ; \mathrm{p}<0.01$ vs. baseline). All patients had decreased mean erythrocyte corpuscular volumes (mean [SD] decrease, 10.4 [6.2] fL; $\mathrm{p}<0.003$ vs. baseline). Thirty percent of the patients experienced clinical improvement in paresthesia, reflex abolition, or combined medullary sclerosis (each, 1 patient). Since this study, $50 \%$ of our patients with Biermer's disease $(n>200)$ have been treated with oral cobalamin therapy.

Nevertheless with regard to curative treatment by orally administered cobalamin, a therapeutic scheme has yet to be definitely validated and true or good indications [8]. In our experience, oral cobalamin therapy should be reserved for primarily hematological consequences of cobalamin deficiency: macrocytic anemia, neutropenia, thrombocytopenia, pancytopenia... hemolysis, microangiopathy thrombotic [5]. To date, it is always recommended to use the parenteral route in severe neurological forms (e.g. medullar sclerosis).

For the choice of oral cobalamin therapy preference, it is necessary to put in the balance that the oral route could curtail or avoid the inconvenience related to discomfort of injections and of likely higher costs (nursing care). It can also be particularly useful in patients under anticoagulant or antiplatelet agent therapy in whom intramuscular injections are contraindicated.

To our despair, despite several studies and years of progress, oral cobalamin therapy in Biermer's disease remains a well-kept medical secret.

\section{References}

1. Toh BH, van Driel IR, Gleeson PA (1997) Pernicious anemia. N Engl J Med 337:1441-1448.

2. Loukili NH, Noel E, Blaison G, Goichot B, Kaltenbach G, et al. (2004) Update of pernicious anemia. A retrospective study of 49 cases. Rev Med Interne 25:556-561.

3. Andrès E, Serraj K (2012) Optimal management of pernicious anaemia. J Blood Med 3:97-103.

4. Nicolas JP, Guéant JL (1994) Absorption, distribution and excretion of vitamin B12. Ann Gastroenterol Hepatol 30: 281-282. 
Citation: Andres E (2017) Oral Cobalamin Therapy for the Patient with Biermer's Disease. J Blood Disord Transfus 8: e117. DOI: 10.4172/2155-9864.1000e117

Page 2 of 2

5. Andrès E, Fothergill H, Mecili M (2010) Efficacy of oral cobalamin (vitamin B12) therapy. Expert Opinion Pharmacotherapy 11:249-256.

6. Kuzminski AM, Del Giacco EJ, Allen RH (1998) Effective treatment of cobalamin deficiency with oral cobalamin. Blood 92:1191-1198.
7. Andrès E, Henoun Loukili N, Noel E (2005) Oral cobalamin (daily dose of $1000 \mu \mathrm{g})$ therapy for the treatment of patients with pernicious anemia. An open label study of 10 patients. Curr Ther Res 66:13-22.

8. Andrès E (2012) Oral cobalamin therapy: it may be perhaps time to propose international recommendations? Presse Med 41:895-898. 